\title{
Anticholinergic blockage of water intake in the Mongolian gerbil
}

\author{
JOEL S. MILNER \\ Western Carolina University, Cullowhee, N.C. 28723
}

Interperitoneal injections of atropine sulfate and atropine methyl nitrate produced a drug and dose-dependent decrease in drinking in water-deprived gerbils. Water intake was more effectively blocked by atropine sulfate than by atropine methyl nitrate. Nevertheless, as both drug dosages increased, water intake decreased. These data support findings in the rat which indicate that drinking is mediated by cholinergically controlled central mechanisms. In addition, however, effective blockage by centrally inactive atropine methyl nitrate suggests that peripheral cholinergic systems may also play a role in regulating drinking behavior in the gerbil.

Intracranial cholinergic chemical stimulation of hypothalamic and limbic sites produces increased water intake in the laboratory rat. Cholinergic blockage of the same brain loci, however, produces depression of drinking (Grossman, 1962, 1964a, b; Miller et al, 1964; Coury, 1967; Hutchinson \& Renfrew, 1967). Central adrenergic stimulation is reported to have little or no direct effect on drinking in the rat. Thus, cholinergic mechanisms are assumed to be of primary importance in regulation of water consumption.

Systemic cholinergic blockage also produces depression of drinking behavior in the rat (Stein, 1963). The effects following systemic injections appear to result from central actions of the cholinergic drugs. Rats injected interperitoneally with centrally active cholinergic blocking agents show a decrease in water intake, while rats injected with centrally inactive cholinergic blocking agents demonstrate no significant change in drinking behavior.

Efforts to reproduce cholinergically coded drinking behavior in species other than the laboratory rat have produced conflicting results. Intracranial chemical-stimulation studies of monkeys (Sharpe, 1969), cats (Milner, 1971), and rabbits (Sommer et al, 1967) suggest species differences in the neurochemical mechanisms underlying the control of drinking behavior. Given the need for more comparative information, the present study examines the effects of a centrally active cholinergic blocking agent, atropine sulfate, and its centrally inactive quaternary analog, atropine methyl nitrate, on water intake in the Mongolian gerbil.

\section{METHOD}

Thirty-one male and female Mongolian gerbils served as experimental Ss. At the start of the study, the animals were 80 days of age and weighed a mean of $55 \mathrm{~g}$. The gerbils were housed individually in a temperature-controlled laboratory which was lighted from 8:00 a.m. to 8:00 p.m. daily. Except for the water-deprivation periods, food (laboratory chow) and distilled water were available ad lib.

Test drugs, which were injected interperitoneally, consisted of the following: $1.0,5.0$, and $10.0 \mathrm{mg} / \mathrm{kg}$ of body weight of atropine sulfate; and $1.0,5.0$, and $10.0 \mathrm{mg} / \mathrm{kg}$ of body weight of atropine methyl nitrate. Mock injections and $0.9 \%$ saline injections were employed as controls. Each injection was given $30 \mathrm{~min}$ prior to $a$ 1-h water-intake test session which followed a 24-, 48-, or 72-h period of water deprivation. All deprivation periods, control injections, and drug concentrations were selected randomly.

Deprivation periods and testing sessions were begun following an initial 5-day cage-habituation period. At least $72 \mathrm{~h}$ elapsed between injections. Additionally, each animal was allowed to regain preexperimental body weight before a new water-deprivation period was begun. Water intakes to the nearest $1 / 2 \mathrm{ml}$ were recorded for the 1-h test sessions. Data were computed in terms of milliliters of intake per $100 \mathrm{~g}$ of body weight.

\section{RESULTS}

Dose-response curves for atropine sulfate and atropine methyl nitrate are presented in Figs. 1 and 2 , respectively. A three-factor analysis of variance with repeated measures on the second two factors was employed to test for statistical significance (Winer, 1962). The analysis indicates that while Factor A (sex) was insignificant $(p>.01)$, both Factors B (deprivation periods) and $\mathrm{C}$ (test injections) were significant beyond the .001 level. All interactions were found to be insignificant $(p>.01)$.

Newman-Keul's multiple range test was used to check for differences between the means of each factor. The test indicates that each of the deprivation period means was significantly different from each of the other means at the .01 level. A test of the differences between the means of Factor C (test injections) showed that the difference between the two control injections was insignificant ( $>.01)$, but all drug concentration means were significantly $(p<.01)$ lower than either of the control injections. Further, except for the

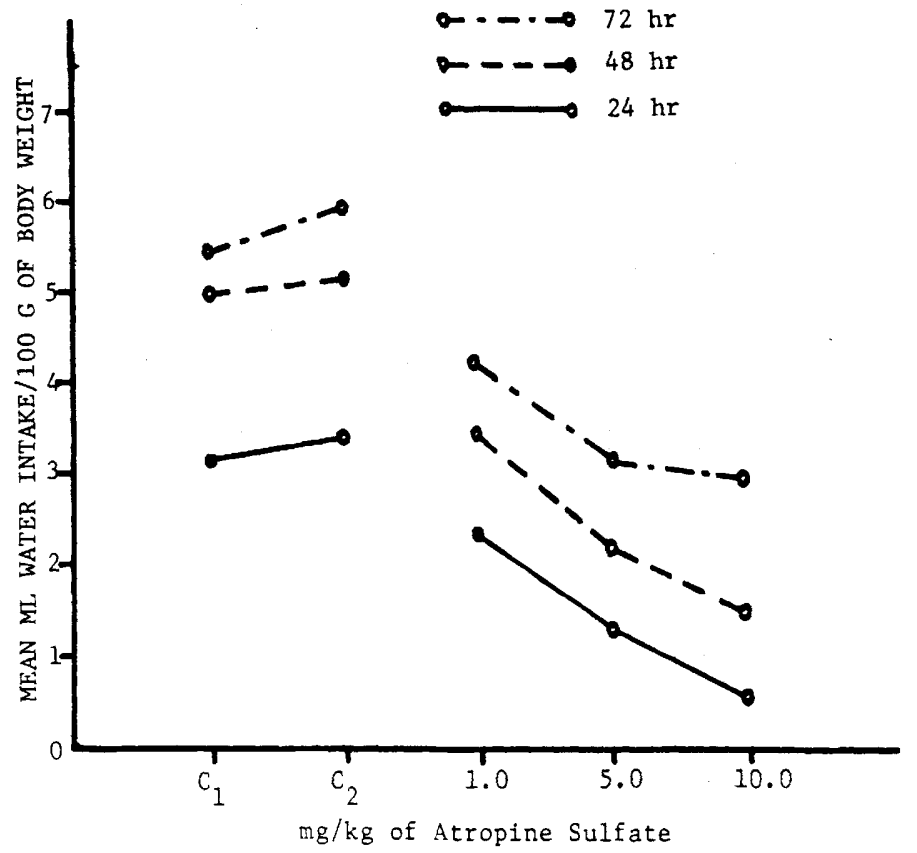

Fig. 1. Effects of atropine sulfate on water intake in gerbils during a 1 - $h$ session following three water-deprivation periods. 


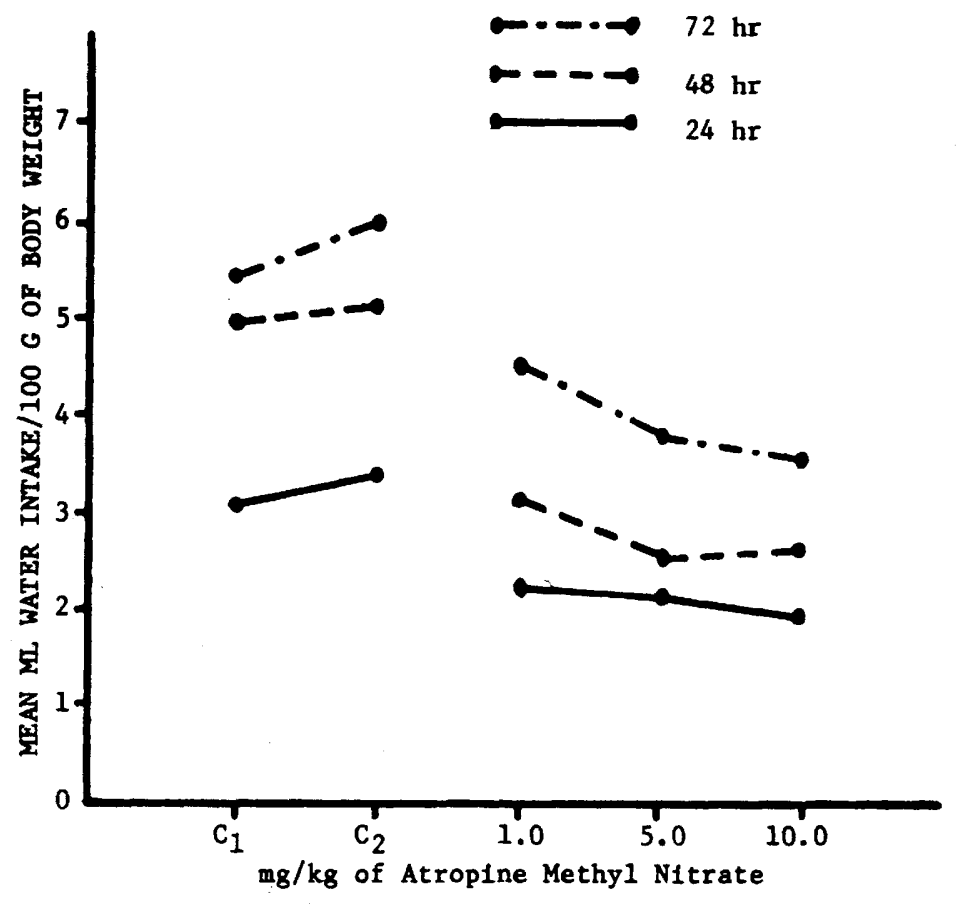

Fig. 2. Effects of atropine methyl nitrate on water intake in gerbils during a 1-h session following three water-deprivation periods.

$5.0-\mathrm{mg} / \mathrm{kg}$ injections of atropine sulfate, the $10.0-\mathrm{mg} / \mathrm{kg}$ injections of atropine sulfate were found to be significantly $(p<.01)$ more effective in blocking drinking behavior than was any other concentration of the two drugs. Sixteen of the thirty-one animals failed to show any measurable water intake following the $10.0-\mathrm{mg} / \mathrm{kg}$ atropine sulfate injection after $24 \mathrm{~h}$ of water deprivation.' Complete suppression of drinking was never observed following control injections. Differences between the intake means for the atropine methyl nitrate concentrations were all insignificant $(\mathrm{p}>.01)$.

\section{DISCUSSION}

Analysis of the dose-response data for atropine sulfate shown in Fig. 1 indicates that, as test concentrations increase, there is a significant decrease in water consumption. Blockage of water intake by systemic injections of atropine sulfate, a centrally active compound, complements similar findings for the laboratory rat (Stein, 1963). However, analysis of the data shown in Fig. 2 indicates that the centrally inactive analog, atropine methyl nitrate, also produces significant blockage of drinking. These results contrast with data reported for the rat. Stein (1963) found that interperitoneal injections of centrally inactive cholinergic blocking agents in rats produced no significant change in water intake.

Of particular interest is the finding that the three dosages of atropine methyl nitrate did not differ significantly in suppression of water intake in the gerbil. These data suggest there is a peripheral blockage effect which becomes maximal in the gerbil following even relative low dosages of atropine methyl nitrate. Additionally, data indicate that the inhibition of drinking following anticholinergic blockage varies significantly with length of deprivation. As water-deprivation periods increase in length, cholinergic blockage of drinking becomes less effective.

In conclusion, the present study supports findings in the rat which suggest that drinking behavior is mediated by cholinergic mechanisms. Further, data indicate that the cholinergic mechanisms regulating water intake may be both central and peripheral in origin in the gerbil. The nature of the suggested peripheral mechanisms is unknown. It does appear, however, that oropharyngeal factors may be ruled out because both atropine compounds cause dryness of the mouth and throat and, hence, would be expected a priori to increase water intake.

\section{REFERENCES}

COURY, J. N. Neural correlates of food and water intake in the rat. Science, 1967. $156,1763-1765$

GROSSMAN, S. P. Direct adrenergic and cholinergic stimulation of hypothalamic mechanisms. American Journal of Physiology, 1962, 202, 872-882.

GROSSMAN, S. P. Behavioral effects of chemical stimulation of the ventral amygdala. Journal of Comparative \& Physiological Psychology, 1964a, 57, 29-36.

GROSSMAN, S. P. Effects of chemical stimulation of the septal area on motivation. Journal of Comparative \& Physiological Psychology, 1964b, 58, 194-200.

HUTCHINSON, R. R., \& RENFREW, J. W. Modification of eating and drinking: Interactions between chemical agent. deprivation state and site of stimulation. Joumal of Comparative \& Physiological Psy chology, 1967, 63, 408-416.

MILNER, N. E., GOTTESMAN, K. S., \& BERRY, N. Dose response to carbachol and norepinephrine in the rat hypothalamus. American Journal of Physiology, 1964, 206, 1384-1388.

MILNER, J. S., NANCE, D. M., \& SHEER D. E. Effects of hypothalamic and a mygdaloid chemical stimulation of appetitive behavior in the cat. Psychonomic Science, 1971, 23, 25-26.

SHARPE, L. G. Chemical stimulation of the diencephalon of the rhesus monkey (Macaca mulatta). Unpublished PhD thesis, Purdue University, 1969.

SOMMER, S. R., NOVIN, D., \& LEVINE, M. Food and water intake after intrahy pothalamic injections of carbachol in the rabbit. Science, 1967, 156, 983-984.

STEIN, L. Anticholinergic drugs and the central control of thirst. Science, 1963, $139,46-48$.

WINER, B. J. Statistical principles in experimental design. New York: McGraw-Hill, 1962. 